\title{
Cadaveric Venous Graft
}

National Cancer Institute

\section{Source}

National Cancer Institute. Cadaveric Venous Graft. NCI Thesaurus. Code C117820.

A venous graft harvested from a cadaver. 